\title{
Trade Center air laden with very fine particles, DELTA scientists find
}

In the most thorough analysis yet of the dust and smoke blown through lower Manhattan after the collapse of the World Trade Center, UC Davis scientists identified unprecedented clouds of very fine particles, which can be riskier to human health than larger, coarse particles.

"The air from Ground Zero was laden with extremely high amounts of very small particles, probably associated with high temperatures in the underground debris pile," says Thomas Cahill, UC Davis professor emeritus of physics and atmospheric sciences. "Normally, in New York City and in most of the world, situations like this just don't exist."

Cahill heads the UC Davis DELTA Group (Detection and Evaluation of Long-range Transport of Aerosols), a collaborative

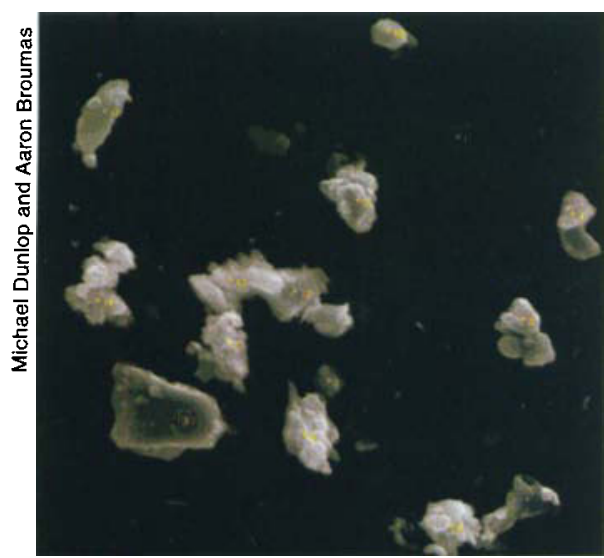

The UC Davis DELTA Group took air samples about a mile from the World Trade Center in early October 2001. several weeks after the towers collapsed. They identified high levels of coarse particles, above, which included powdered concrete and glass with a coating of combustion products, in size range of 5 to 12 micrometers diameter. Very fine particles were found at levels not previously seen in ambient air samples. association of aerosol scientists at several universities and national laboratories, which monitors atmospheric conditions associated with global warming, weather, disasters and other events.

The DELTA Group collected air samples at the request of the U.S. Department of Energy from Oct. 2 through mid-December, with a rooftop air monitor about 1 mile north-northeast of Ground Zero.

The results for October were released in early February, and Cahill testified at an investigative hearing before the national ombudsperson for the U.S. Environmental Protection Agency on Feb. 23.

The samples were collected continuously in eight separate-size modes from coarse (12 micrometers diameter) to ultra-fine ( 0.09 micrometers diameter), and were analyzed for dozens of substances that are likely to be associated with burning office buildings.

Coarse particles are typically filtered by the nose or coughed out of the throat and upper lungs, but they can irritate the mucous membranes and aggravate pre-existing breathing problems such as asthma. Very fine particles, however, can travel deep into human lungs, and are typically removed from the lungs through the bloodstream and heart, increasing the possibility of more serious health impacts.

In the largest spike, the DELTA Group analysis found 58 micrograms per cubic meter of very fine particles in one 45-minute period - "an extremely high peak," Cahill says. "Even on the worst air days in Beijing, downwind from coalfired power plants, or in the Kuwaiti oil fires, we did not see these levels of very fine particulates."

Virtually all the air samples from the trade center site also carried high concentrations of coarse particles. "These particles simply should not be there," Cahill says. "It had rained, sometimes heavily, on 6 days in the prior 3 weeks. That rain should have settled these coarse particles." The finding suggests that coarse particles were being continually generated from the hot debris pile.

Some metals in the very fine mode, such as vanadium, were found at the highest levels ever recorded in air in the United States. Although some asbestos was used in the buildings for fireproofing and in floor tiles, the DELTA group found very few asbestos fibers, even in the very fine particles.

All evidence indicates that ambient air in New York City is no longer influenced by the World Trade Center collapse, especially since the fires are out and the debris pile has cooled, Cahill says. However, the presence of large amounts of very fine particles as late as October means that the cleanup of indoor air should be undertaken carefully, he warns. Very fine particles penetrate crevices and fabrics in a way that normal dust doesn't, and they are easily resuspended, which can re-expose the room's occupants.

For more information, go to: http://delta.ucdavis.edu.

\section{Carbon dioxide hampers nitrate incorporation by plants}

Nitrate fertilizer is not nearly as efficient as ammonium fertilizer when atmospheric carbon dioxide levels are unusually high, according to a study by two UC Davis professors.

Rising levels of atmospheric carbon dioxide associated with global warming - can interfere with a plant's ability to incorporate nitrogen, Arnold Bloom and David Smart reported in the Feb. 5 Proceedings of the National Academy of Sciences. Carbon dioxide concentrations have increased by an estimated $30 \%$ during the past two centuries and are likely to double during the next century.

Farmers and gardeners commonly apply nitrogen-rich fertilizers to their crops in order to enhance yields. The UC Davis scientists studied 
how wheat plants respond to being fertilized with two different forms of nitrogen, nitrate and ammonium, under varying concentrations of atmospheric carbon dioxide.

The plants receiving ammonium responded much more to the increased carbon dioxide than did the plants receiving nitrate, the scientists found. Elevated carbon dioxide levels inhibited the processing of nitrate in the wheat leaves. When atmospheric carbon dioxide rose to nearly twice the normal level, the leaves of plants receiving ammonium increased in size by nearly $49 \%$, while plants receiving nitrate increased by only $24 \%$.

Additionally, the protein content of the wheat plants receiving ammonium increased $73 \%$ under elevated carbon dioxide, compared to only $32 \%$ for those receiving nitrate, suggesting that rising atmospheric carbon dioxide levels might diminish the nutritional quality of grain receiving nitrate fertilizer. The work has since been repeated in tomatoes, with similar results.

"We expect that the data will have real-world implications for crop production," Bloom says. "In well-drained soils generally devoted to wheat production, nitrate is the common form of nitrogen available. The study suggests that a shift to increase ammonium availability might be needed."

Furthermore, plant and tree species in natural ecosystems that depend on nitrate conversion into amino acids in their leaves are likely to be at a competitive disadvantage with those species that are either able to convert nitrate into amino acids in their roots or use ammonium as their predominant nitrogen source. "This may result in significant changes in the distribution of plants in the wild as atmospheric carbon dioxide levels continue to rise," Bloom says.

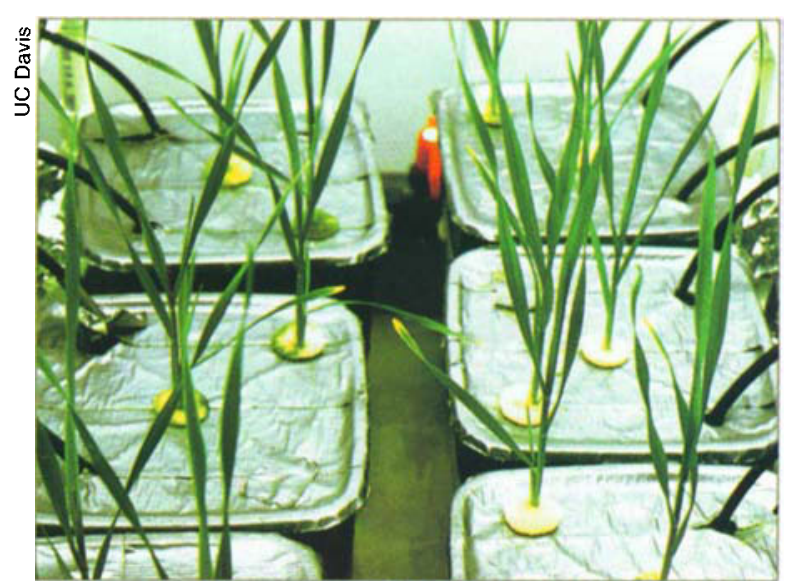

Wheat was grown in a controlled environmental chamber under elevated carbon dioxide. Plants received ammonium (left) or nitrate (right) as their sole nitrogen source. Leaves of plants receiving nitrate are yellowish-green, signaling that they are not assimilating the nutrient as well as plants receiving ammonium.

\section{Super-sensitive nitrogen dioxide detector identifies greenhouse gases}

With the aid of the most sensitive nitrogen dioxide detector in the world, UC Berkeley chemists can now quantify certain important contributors to air pollution and global warming.

Human-made nitrogen oxide compounds are emitted by automobiles, industrial smokestacks and other sources; they react with natural hydrocarbons from vegetation to produce ozone smog. "Ozone in the troposphere has doubled in the past century, contributing $10 \%$ to $15 \%$ of the human additions to the greenhouse effect," says UC Berkeley chemistry professor Ronald C. Cohen. "All of this is driven by nitrogen oxides."

Until now, however, as much as half the resulting nitrogen oxides have been unaccounted for in the atmosphere,

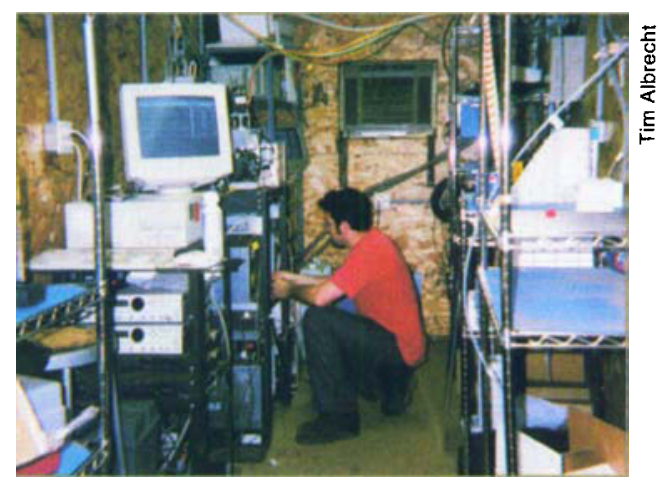

Doug Day checks the performance of the world's most sensitive nitrogen dioxide detector, in a trailer at the UC Blodgett Forest Research Center in EI Dorado County. The detector found high levels of previously unquantified organic nitrogen compounds, an observation that current models cannot adequately explain. leaving air pollution models incomplete. Today's smog monitors measure essentially the sum total of all nitrogen oxides in the air, and are unable to break them down into the specific amount of each nitrogen oxide-containing chemical.

Over about 4 years, Cohen and his laboratory colleagues developed a new detector, called thermal dissociation-laser induced fluorescence (TD-LIF), which can monitor nitrogen oxide compounds continuously with sensitivity down to 30 parts per trillion. The technique is a thousand times more sensitive than needed for today's pollution monitoring and sensitive enough for studies in remote locations.

Deploying the detector in downtown Houston and in a remote Sierra Nevada forest, the scientists detected large amounts of organic nitrogen oxide compounds called alkyl nitrates, which were thought to be only a minor constituent of smog.

"If we want to understand quantitatively the effect of local pollution on the global scale, we need to know how and in what form nitrogen oxide is transferred to the rest of the globe," Cohen says.

The research was published in the March 2002 issue of the Journal of Geophysical ResearchAtmospheres, and is supported by the National Aeronautics and Space Administration.

\section{- Compiled from UC and other news sources}

